\title{
Environmental assessment of technology investments using the LCA Polygon framework
}

\author{
D. A. Georgakellos \\ Department of Business Administration, University of Piraeus, Greece
}

\begin{abstract}
This paper presents a novel framework to aid assessment and selection in certain technology investments projects. Since most of the methods available for this purpose consider factors that seem to focus almost exclusively on what creates most net value to the buyer of a technology system, ignoring the external costs associated with this system, the technique proposed here has been developed in order to provide a tool for the integration of the environmental externalities in the assessment and selection process. This tool uses the findings of Life Cycle Assessments (LCAs) and especially the outcomes of the LCA Polygon approach in order to consider for each possible alternative its environmental performance together with any economic aspects, and to result into a single "score", i.e. the relative external cost. This value could be used as the exclusive basis for the comparative appraisal of the candidates, or it could be easily integrated in most of the existing decision methods. A relevant case study is also included in the paper to illustrate the proposed framework. It is about the assessment of an investment concerning five different vehicle technologies. The result of this application can be easily incorporated in almost any common decision-making model, which intends to take into consideration the externalities of its choice.

Keywords: investment assessment, technology selection, external cost, environmental externalities, life-cycle assessment, LCA polygon, vehicle technologies.
\end{abstract}

\section{Introduction}

In general, the assessment and selection of technology investments falls into three general classes of problems: (a) accept-reject problems require an assessment of whether an investment is worthwhile, (b) selection of the best 
project from a set of mutually exclusive projects is required when there are several competing projects or options and only one of them can be built or purchased, and (c) capital budgeting problems are concerned with the selection of a set of projects when there is a budget constraint and many, not necessarily competing, options [1]. The present paper is focused on the second of these classes. Many precision-based methods for technology investments selection have been developed. Most of them are based on traditional supplier selection methods and purchasing decision models. In this context, contemporary operations research offers a range of methods and techniques that may support the decision-maker in many technology investments selection processes [2]. All selection techniques are based on a number of criteria, tangible (technical or economic) and intangible (analytical) [3]. However, almost all of the technology investments assessment and selection techniques consider factors, no matter tangible or intangible, which seem to focus almost exclusively on what creates most net value to the investor or the buyer of technology [4]. In other words, the environmental externalities associated with every choice, in most of the cases, are not taken into consideration. The term externality means a third-party effect associated with production or consumption. If the external effect generates costs to a third party it is a negative externality $[5,6]$. In this context, the present work intends to provide a framework for the integration of these externalities in the technology investment assessment and selection process. This is being achieved by the use of the Life Cycle Assessment (LCA) Polygon framework in the sections that follow. This framework has been developed for evaluating the results of a Life Cycle Inventory Analysis using critical volume aggregation and polygon-based interpretation [7]. Furthermore, an application of this framework is also presented in order to provide useful information about it by highlighting its principal advantages and weaknesses. This application concerns the environmental assessment and selection of alternative vehicle technology investments. The evaluated technologies are internal combustion engine vehicles (ICEV), hybrid electric vehicles (HEV) and fuel-cell vehicles (FCEV) that use methanol as energy carrier, fuel-cell vehicles (FCEV) using hydrogen as energy carrier, and battery-powered electric vehicles (BPEV) that use electricity.

\section{Literature review}

In the literature several dimensions are mentioned that are important in the investments assessment and selection process. These include net price, quality, delivery, performance history, capacity, communication system, service, geographical location, etc [8]. The problem is how to select manufacturers and suppliers that perform optimally on the desired dimensions. The published relevant selection decision models formulate answers to this multiple objective problem. Some authors propose linear weighting models in which suppliers are rated on several criteria and in which these ratings are combined into a single score. Others propose mathematical programming formulations in which quantifiable criteria are taken into account. Some approach the problem on an item-by-item basis; others consider it a multiple item decision [9]. The vast 
majority of the decision models apply to the final choice phase of the selection process. Decision models of this kind, which are usually based on several multicriteria, mathematical programming, and other advanced methodologies [10], are mainly linear weighting models, mathematical programming models and the total cost of ownership models. In linear weighting models weights are given to the criteria, the biggest weight indicating the highest importance. Ratings on the criteria are multiplied by their weights and summed in order to obtain a single figure for each supplier. The supplier with the highest overall rating can then be selected. A mathematical programming model allows the decision-maker to formulate the decision problem in terms of a mathematical objective function that subsequently needs to be maximized (e.g. maximize profit) or minimized (e.g. minimize costs) by varying the values of the variables in the objective function [2]. Total cost of ownership (TCO) models attempt to include all quantifiable costs in the supplier choice that are incurred throughout the purchased item's life cycle. Effective TCO valuation requires the use of activitybased costing systems $[8,11]$. TCO-based models have been developed not only for the manufacturing sector but for the purchasing of a service as well [12], while TCO is a term that is frequently used in Information Technology cost management literature, although often with different meanings [13]. Other decision models for the final choice-phase are artificial intelligence (AI) based models and statistical models. AI-based models are based on computer-aided systems that in one-way or another can be "trained" by historic data Statistical models deal with the stochastic uncertainty related to the vendor choice. Although stochastic uncertainty is present in most types of purchasing situations, only very few supplier choice models really handle this problem. Apart from the decision models that apply to the final choice-phase of the selection process, there are also methods for problem definition and formulation of criteria, as well as decision methods for pre-qualification of suitable vendors. Decision methods for problem definition are methods that support the decision-maker in carefully questioning the need for a decision and the alternatives that seem to be available, while the aim of the decision methods for pre-qualification is mainly to sort rather than rank the candidate investments (equipment and technologies) together with their suppliers. Some of the methods for pre-qualification, which could be used in the final choice as well, are categorical methods, cluster analysis, casebased-reasoning systems and data envelopment analysis $[2,14]$.

Most of the models presented above may prove to be useful for ordinary projects concerning technology investments assessment and selection. It must be noted, though, that almost none of these tools takes into account, among other selection criteria, environmental aspects. In other words, the selection process is based, almost always, on criteria like net price, technical performance, capacity, quality, delivery or service, while criteria arising from the environmental performance of the candidates and the subsequent externalities associated with their production and/or use are disregarded. Because of this fact, the relevant literature has been, to our knowledge, extremely limited. For instance, in a recent work, life cycle electricity and environmental impacts for computer tape drives have been combined with TCO philosophy. However, the aim of this attempt 
was not to give a specific decision tool but just to make an estimate of the different impacts of manufacturing versus use-phase impacts of this product [15]. On the contrary, the development of such a tool is the purpose of a similar work [16] but, in order to apply the proposed there model one needs to know (for each candidate under evaluation) the average external cost as well as the average environmental impacts associated with this cost, which may be not so easy for most of the cases. This weakness does not exist in the proposed in the following sections framework.

\section{Methodology overview}

In the proposed here framework, the basis for making the comparison is the Life Cycle Inventory Analysis of each product. This is very usual in environmental decision-making $[17,18]$. However, such analyses provide a large amount of multi-dimensional data (inputs and outputs) that are difficult to comprehend and to interpret. Therefore, Life Cycle Inventories need to be aggregated to be of much use [19]. However, care should be taken when aggregating the inputs and outputs in the product system, as adding up data always involves a procedure that implies making value judgments on the relative importance of the impacts and the criteria considered $[20,21]$. Thus, there has been a debate going on for many years, where several authors express their dissent of the one number concept fearing that the transparency will be lost when an environmental impact is described in one number, like in an index. On the other side, designers often express their need for practical tools that may be used in their everyday life [22, 23]. In this context, an appropriate method has been developed as a tool to aid the comparative appraisal of products according to their environmental performance. This methodology (known as "polygon-based" one) has been developed for the interpretation of LCA results [7].

A low-level aggregation describing the addition of single inventory inputs and outputs defined in the same measuring units is the first step. After low-level aggregation, which is incorporated in most Life Cycle Inventories, some of the inventory inputs and outputs (such as energy consumption) are expressed by a single value, while others (such as atmospheric emissions) are not and a further aggregation is needed. This is high-level aggregation, which allows the aggregation of inputs and outputs that are defined in different measuring units. High-level aggregation involves conversion of data. In the polygon-based method, the aggregation algorithm makes use of weights that reflect threshold values of pollutants. Specifically, in order to add and to compare different air or water pollutants, it is possible to calculate the so-called critical air or water mass or volume. It denominates the mass or volume of air and water that would be necessary to dilute the emission to such an extent that the concentration permitted by the threshold value is just reached. To calculate this critical mass or volume, the recorded emission (expressed in quantity terms) is divided by the threshold value. If the obtained masses or volumes of the emitted pollutants are added, this value can be used as a sum parameter for the air and water pollution. This total critical mass or volume is given by the following equation: 


$$
C R=\sum_{i=1}^{n} \frac{p_{i}}{T L_{i}}
$$

where $\mathrm{CR}$ is the total critical mass or volume of air or water, $\mathrm{p}_{\mathrm{i}}$ is the amount of pollutant $\mathrm{i}$ (for $\mathrm{i}=1, \ldots, \mathrm{n}$ ), and $\mathrm{TL}_{\mathrm{i}}$ is the threshold value of pollutant $\mathrm{i}$ (for $\mathrm{i}=1, \ldots, \mathrm{n})$.

Toxicological, ecological, medical or political criteria can play a role for the determination of the threshold values $\left(\mathrm{TL}_{\mathrm{i}}\right)$. For instance, environmental regulatory standards can be used for this purpose. However, they have received a lot of criticism, as they often present a number of drawbacks. For these reasons, their use is therefore often advised against [20, 24, 25].

Afterwards, the total critical masses or volumes, or any other impact that results from a low-level or a high-level aggregation procedure of the inventory inputs and outputs could be selected and used as ecological parameters "EP". In order to "transform" these ecological parameters to a single value, a further aggregation is needed. This is achieved according to the procedure that follows. Assuming that " $r$ " products are under examination and comparison, and that the eco-profile of each product consists of " $\mathrm{m}$ " ecological parameters, then for every product under examination and for each one of its ecological parameters $\mathrm{EP}_{\mathrm{j}, \mathrm{k}}(\mathrm{j}=1, \ldots, \mathrm{m}$ and $\mathrm{k}=1, \ldots, \mathrm{r})$, a relative grade is calculated as follows:

$$
R G_{j, k}=\frac{E P_{j, k}}{E P_{j, \max }} \quad \text { for } \mathrm{j}=1, \ldots, \mathrm{m} \text { and } \mathrm{k}=1, \ldots, \mathrm{r}
$$

where $\mathrm{RG}_{\mathrm{j}, \mathrm{k}}$ is the relative grade of the ecological parameter $\mathrm{j}$ for the product $\mathrm{k}$, $\mathrm{EP}_{\mathrm{j}, \mathrm{k}}$ is the ecological parameter $\mathrm{j}$ of the product $\mathrm{k}$, and $\mathrm{EP}_{\mathrm{j}, \max }$ is the largest ecological parameter $\mathrm{j}$, i.e. $\mathrm{EP}_{\mathrm{j}, \max } \geq \mathrm{EP}_{\mathrm{j}, \mathrm{k}}$ for $\mathrm{k}=1, \ldots, \mathrm{r}$

Afterwards, for every product $\mathrm{k}(\mathrm{k}=1, \ldots, \mathrm{r})$ under examination, all its relative grades $\mathrm{RG}_{\mathrm{j}, \mathrm{k}}(\mathrm{j}=1, \ldots, \mathrm{m})$ are put in a radar diagram. In this chart type, each category has its own value axis radiating from center point. In our case, each relative grade $R G_{j, k}$ has its own axis scaled from 0 to 1 . Lines connect all the values forming a polygon. In general, a radar diagram compares the aggregate value of a number of data series. Therefore, it is evident that the product that covers the most area represents the worst environmental performance. In other words, the best product is this one, which has the lowest polygon area. The environmental impacts of a product can therefore be expressed in a single index number (the polygon area), which is unambiguously comparable to the index number for substitute or competing products and materials. This is not the first time that this kind of diagrams is used to illustrate environmental impact data. A quite similar approach is this of target plots, which have been developed as an overall assessment of a product design according to the Design for the Environment concept [26].

Finally, for each candidate $\mathrm{k}(\mathrm{k}=1, \ldots, \mathrm{r})$ its relative external cost is calculated, as follows: 


$$
R C_{k}=S_{k} E C \quad \text { for } \mathrm{k}=1, \ldots, \mathrm{r}
$$

where $R C_{k}$ is the relative external cost of the candidate $\mathrm{k}, S_{k}$ is the polygon area of the candidate $\mathrm{k}$, and $E C$ is the average external cost of a typical product or process in the industrial or economic sector of the candidates.

The relative external cost could be used as the exclusive basis for the comparative appraisal of the candidates (in such a choice the best candidate is this one which has the lowest relative external cost $\mathrm{RC}_{\mathrm{k}}$ ), or it could be easily integrated in most of the technology selection decision methods (like these ones presented in the previous section). For instance, $\mathrm{RC}_{\mathrm{k}}$ can be considered, together with other costs that incurred throughout the candidates' life cycle and are include in a TCO-based model, to adjust the unit price quoted. Likewise, it can be used as one more criterion, among other criteria used, in a linear weighting model, or as one more variable in any other similar method.

\section{Case study}

In the present case study, various technologies are analyzed for a typical midsize passenger car. In particular, the vehicle technologies under examination in the present work are the following: (a) ICEV using methanol as energy carrier, (b) HEV using methanol as energy carrier, (c) FCEV using methanol as energy carrier, (d) FCEV using hydrogen as energy carrier, and (e) BPEV, using electricity as energy carrier. In our case, the primary energy source for both methanol and hydrogen is cellulosic biomass. Regarding electricity, it is assumed that the primary energy sources of the electric energy used by BPEV are theoretical energy systems fully based on renewable sources. The main sources of data that have been used to compare the average energy use and emission of the vehicles studied is the relevant study of Johansson and Åhman, [27]. Specifically, the data used here are given in table 1 and concerns energy use and emissions of nitrogen oxides (NOx), volatile organic compounds (VOC), particulate matters $(\mathrm{PM})$ and carbon dioxide $\left(\mathrm{CO}_{2}\right)$.

Table 1: $\quad$ Ecological parameters for the vehicles studied

\begin{tabular}{|c|c|c|c|c|c|c|}
\hline & Unit & ICEV & HEV & $\begin{array}{c}\text { FCEV } \\
\text { methanol }\end{array}$ & $\begin{array}{c}\text { FCEV } \\
\text { hydrogen }\end{array}$ & BPEV \\
\hline Energy use & $\mathrm{kWh} / 10 \mathrm{~km}$ & 4 & 3 & 3,2 & 2,6 & 1,7 \\
\hline $\mathrm{NOx}$ & $\mathrm{g} / \mathrm{km}$ & 0,06 & 0,04 & 0,04 & 0,03 & 0,04 \\
\hline $\mathrm{VOC}$ & $\mathrm{g} / \mathrm{km}$ & 0,043 & 0,010 & 0,010 & 0,008 & 0,001 \\
\hline $\mathrm{PM}$ & $\mathrm{g} / \mathrm{km}$ & 1,20 & 0,90 & 0,96 & 0,78 & 2,50 \\
\hline $\mathrm{CO}_{2}$ & $\mathrm{~g} / \mathrm{km}$ & 12,0 & 9,0 & 0,6 & 0,78 & 1,5 \\
\hline
\end{tabular}

Since the comparison basis in the present case consists of merely five environmental impacts (energy use and emissions of $\mathrm{NOx}, \mathrm{VOC}, \mathrm{PM}$ and $\mathrm{CO}_{2}$ ), it is not necessary to aggregate them. Thus the eqn (1) of the polygon-based method is not being applied here, while the ecological parameters for each vehicle technology are: (1) energy use, (2) NOx emissions, (3) VOC emissions, 
(4) PM emissions and (5) $\mathrm{CO}_{2}$ emissions. Obviously, table 1 presents these ecological parameters as well. Subsequently, applying the eqn (2), the relative grades for each one of the ecological parameters of table 1 are calculated and presented in table 2 . In our case it is $r=5$ (i.e. $k=1, \ldots, 5)$ and $m=5$ (i.e. $j=1, \ldots, 5$ ).

Table 2: Relative grades of the ecological parameters of the examined vehicles.

\begin{tabular}{|c|c|c|c|c|c|c|}
\hline & Unit & ICEV & HEV & $\begin{array}{c}\text { FCEV } \\
\text { methanol }\end{array}$ & $\begin{array}{c}\text { FCEV } \\
\text { hydrogen }\end{array}$ & BPEV \\
\hline Energy use & $\%$ & 100 & 75 & 80 & 65 & 42,5 \\
\hline NOx & $\%$ & 100 & 66,67 & 66,67 & 50 & 66,67 \\
\hline VOC & $\%$ & 100 & 23,26 & 23,26 & 18,6 & 2,33 \\
\hline $\mathrm{PM}$ & $\%$ & 48 & 36 & 38,4 & 31,2 & 100 \\
\hline $\mathrm{CO}_{2}$ & $\%$ & 100 & 75 & 80 & 65 & 12,5 \\
\hline
\end{tabular}

Then, putting the calculated grades in a radar diagram, the polygon for each vehicle technology is formed. According to the area of each polygon, the five vehicle technologies can be easily ranked and compared. Specifically, the polygon area, as a percentage of the total area of the radar diagram, is $79,20 \%$ for ICEV, 29,30\% for HEV, 31,94\% for FCEV (methanol), 20,27\% for FCEV (hydrogen) and 16,88\% for BPEV. Finally, applying the eqn (3) and based on the above polygon areas as well as on the average external cost which is $68 € / 1000$ pkm for passenger transport in Greece [28], the relative external cost $\left(\mathrm{RC}_{\mathrm{k}}\right)$ for the five vehicles is calculated: $53,9 € / 1000 \mathrm{pkm}$ for ICEV, 19,9€/1000 pkm for $\mathrm{HEV}, 21,7 € / 1000 \mathrm{pkm}$ for FCEV (methanol), 13,8 €/1000 pkm for FCEV (hydrogen), and 11,5€/1000 pkm for BPEV. These values can be used in a typical investment selection model as a criterion together with other ones concerning the technical and commercial features of the candidates. Alternatively, they can be used in TCO-based decision model as follows: given that in Greece the load factor is 1,98 passengers per vehicle [28], the total annual mileage per vehicle $13.000 \mathrm{~km} / \mathrm{yr}$ and that the mean passenger vehicle age is about 10,2 yr [29], the total environmental external cost occurred during the useful life time of the five candidates is $14.151 €$ for ICEV, $5.225 €$ for HEV, $5.697 €$ for FCEV - methanol, $3.623 €$ for FCEV - hydrogen and $3.019 €$ for $\mathrm{BPEV}$. These values can be taken into consideration, together with all other costs that incurred throughout the life cycle of the five vehicle technologies, to assist the final choice, by modifying their price accordingly as it is shown in table 3 .

Table 3: Acquisition, average external and total cost of the examined vehicles.

\begin{tabular}{|c|c|c|c|c|c|c|}
\hline & Unit & ICEV & HEV & $\begin{array}{c}\text { FCEV } \\
\text { methanol }\end{array}$ & $\begin{array}{c}\text { FCEV } \\
\text { hydrogen }\end{array}$ & BPEV \\
\hline Acquisition Cost & $€$ & 16.000 & 17.650 & 17.250 & 20.900 & 15.100 \\
\hline Av. External Cost & $€$ & 14.151 & 5.225 & 5.697 & 3.623 & 3.019 \\
\hline Total Cost & $€$ & 30.151 & 22.875 & 22.947 & 24.523 & 18.119 \\
\hline
\end{tabular}




\section{Concluding remarks}

Since almost all of the methods available for technology investments assessment and selection consider factors that seem to focus almost exclusively on what creates most net value to the buyer of a technology system, ignoring the external costs associated with this system, the proposed here framework has been developed in order to provide a tool for the integration of the environmental externalities in the assessment and selection process. This tool is based on the findings of Life Cycle Assessments and especially the LCA Polygon approach. The strong points of the framework is that it is easy to understand and easy to use. Moreover, it is not very data and effort consuming. Regarding the latter, the required data for the application of the procedure is the environmental performance of the candidates as well as information concerning the average external cost in a particular area of a typical, similar to the candidates, product or process. LCA findings can be used as a good source for the environmental performance of the candidates, while the general literature can easily provide information on the average external cost for a steadily growing number of products and processes. Another positive point of the method is that the outcome of the proposed here procedure could be considered, together with all other costs, in a total cost of ownership model adjusting the price offered, or it could be included in a linear weighting model as one of the criteria used. Aside from the above, it can also be used as the exclusive base for the comparative appraisal of the candidates. In such a case, this method allows a clear conclusion as it leads to single value (the relative external cost), which is unambiguously comparable.

Regarding the drawbacks of the method, one could mention that at high-level aggregation the related algorithm makes use of weights that reflect threshold values of pollutants. Therefore, a common weakness in this kind of procedures is that they are based on national emission levels and standards, which are really only valid in the country in question. Moreover, policy standards and goals may be of different dignity and therefore they are not a good indicator of what emissions are the most severe. This is a valid critique if the goals have been developed separately and for purposes other than weighting; if, however, goals conflicts have been discussed explicitly in the policy making process, the critique is less valid. Another weak point of proposed framework is that it heavily depends on the quality of the information used. In certain cases, uncertainties of this information may be considerable, because there are not enough measured data while the available form various sources data are not always consistent. There are numerous sources of uncertainty in this kind of information. Some of the more important include old data, incomplete data, missing data, data aggregation etc. It is evident that all these sources of uncertainty may affect the outcome of the method.

An example of a comparative appraisal application is also presented in the paper to illustrate the proposed framework. It is about the assessment of an investment concerning five different vehicle technologies. The result of this application is a single value for each candidate that can be easily incorporated in 
almost any common decision-making model, which intends to take into consideration the externalities of its choice.

\section{References}

[1] Hendrickson, C. \& McNeil, S., Project selection from alternatives. Technology Management Handbook, ed. R.C. Dorf, CRC Press LLC: Boca Raton, 1999.

[2] De Boer, L., Labro, E. \& Morlacchi, P., A review of methods supporting supplier selection. European Journal of Purchasing and Supply Management, 7, pp.75-89, 2001.

[3] Chan, F.T.S., Chan, M.H. \& Tang, N.K.H., Evaluation methodologies for technology selection. Journal of Materials Processing Technology, 107, pp. 330-337, 2000 .

[4] Janszen, F., The age of innovation, Financial Times / Prentice Hall: London, 2000.

[5] Field, B.C., Environmental economics - An introduction, McGraw Hill Int. Eds: New York, 1997.

[6] Callan, S.J. \& Thomas, L.M., Environmental economics and management - Theory, policy, and applications, The Dryden Press: Orlando, 2000.

[7] Georgakellos, D.A., Evaluation of life cycle inventory results using critical volume aggregation and polygon-based interpretation. Journal of Cleaner Production, 13, pp. 567-582, 2005.

[8] Degraeve, Z. \& Roodhooft, F., Improving the efficiency of the purchasing process using total cost of ownership information: The case of heating electrodes at Cockerill Sambre S.A. European Journal of Operational Research, 112, pp. 42-53, 1999.

[9] Degraeve, Z., Labro, E. \& Roodhooft, F., An evaluation of vendor selection models from a total cost of ownership perspective. European Journal of Operational Research, 125, pp. 34-58, 2000.

[10] Talluri, S. \& Narasimhan, R., Vendor evaluation with performance variability: A max-min approach. European Journal of Operational Research, 146, pp. 543-552, 2003.

[11] Plank, R.E. \& Ferrin, B.G., How manufacturers value purchase offerings. An exploratory study. Industrial marketing management, 31, pp. 457-465, 2002.

[12] Degraeve, Z., Labro, E. \& Roodhooft, F., Total cost of ownership purchasing of service: The case of airline selection at Alcatel Bell. European Journal of Operational Research, 156(1), 23-40, 2004.

[13] Van Maanen, H. \& Berghout, B., Cost management in IT beyond cost of ownership models: a state of the art overview of the Dutch financial services industry. Evaluation and Program Planning, 25, pp.167-173, 2002.

[14] Easton, L., Murphy, D.J. \& Pearson, J.N., Purchasing performance evaluation: with data envelopment analysis. European Journal of Purchasing and Supply Management, 8, pp.123-134, 2002. 
[15] Matthews, H.S., Use versus manufacture life cycle electricity and environmental impacts for computer tape drives. Resources, Conservation and Recycling, 36, pp. 187-196, 2002.

[16] Georgakellos, D.A., Considering externalities in decision-making: Integration of the LCA approach in technology selection process. American Journal of Applied Sciences, 2(1), pp. 387-393, 2005.

[17] Hassan, O.A.B., A value-focused thinking approach for environmental management of buildings construction. Journal of Environmental Assessment Policy and Management, 5(2), pp. 247-261, 2003.

[18] Ison, E. \& Miller, A., The use of LCA to introduce life-cycle thinking into decision-making for the purchase of medical devices in the NHS. Journal of Environmental Assessment Policy and Management, 2(4), pp. 453-476, 2000.

[19] Rubik, F. \& Baumgartner, T., Technological innovations in the plastics industry and its influence on the environmental problems of plastic waste - Evaluation of Eco-balances, Commission of the European Communities: Luxembourg, 1992.

[20] Guinée, J.B. (ed.), Handbook on Life Cycle Assessment - Operational guide to the ISO standards, Kluwer Academic Publishers: Dordrect, 2002.

[21] Jensen, A.A., Hoffman, L., Møller, B.T., Schmidt, A., Christiansen, K., Elkington, J. \& van Dijk, F., (1997). Life Cycle Assessment - A guide to approaches, experiences and information sources, European Environment Agency: Copenhagen, 1997.

[22] Steen, B., A Systematic approach to environmental priority strategies in product development (EPS). Version 2000 - General system characteristics, Chalmers University of Technology: Göteborg, 1999.

[23] Van der Vorst, R., Grafé-Buckens, A. \& Sheate, W.R., A systematic framework for environmental decision-making, Journal of Environmental Assessment Policy and Management, 1(1), pp. 1-26, 1999.

[24] Bengtsson, M. \& Steen, B., Weighting in LCA - Approaches and applications. Environmental Progress, 19(2), pp. 101-109, 2002.

[25] Finnveden, G., A critical overview in operational valuation/weighting methods for Life Cycle Assessment, Swedish Environmental Protection Agency: Stockholm, 1999.

[26] Graedel, T.E., Streamlined Life-cycle Assessment, Prentice Hall: Upper Saddle River, 1999.

[27] Johansson, B. \& Åhman M., A comparison of technologies for carbon neutral passenger transport. Transportation Research Part D, 7, pp. 175196, 2002.

[28] European Environment Agency, External costs of transport: Version 2008-2001, EEA: Copenhagen, 2001.

[29] LAT/AUTH, Methodologies for estimating air pollutant emissions from transport. Road traffic composition, LAT Report No: 9823, Aristotle University of Thessaloniki: Thessaloniki, 1998. 